\title{
A GÊNESE DO “SISTEMA TRIBUTÁRIO BRASILEIRO”, SUAS VICISSITUDES E A DESCONEXÃO DA IDEOLOGIA SISTEMÁTICA EUROPEIA
}

\author{
Vicente de Paulo Augusto de Oliveira Júnior ${ }^{1}$
}

RESUMO: O presente trabalho tem por objetivo a investigação da gênese do conceito de "sistema tributário brasileiro", na qual se utilizou, pelo método lógico-dedutivo, de uma abordagem comparativa da situação jurídico-política brasileira para com a das demais nações, primordialmente as europeias. Diante das modificações enfrentadas em solo europeu, e o surgimento do movimento juspositivista, passa-se a analisar o sistema jurídico tributário, sob as influências positivistas, que levaram, após algumas tentativas de correção de tradicionais problemas jurídico-políticos nacionais, como a distribuição de renda, critérios díspares de tributação, entre outros, a emergir a necessidade de uma codificação.

PALAVRAS-CHAVE: Sistema Tributário Brasileiro; Brasil Colônia; Ideologia Sistemática Europeia; Movimento juspositivista; Codificação tributária.

\section{THE GENESIS OF THE "BRAZILIAN TAX SYSTEM", ITS VICISSITUDES AND THE DISCONNECTION OF THE SYSTEMATIC IDEOLOGY EUROPE}

ABSTRACT: The present work aims to investigate the genesis of the concept of "Brazilian tax system", in which, by the logical-deductive method, a comparative approach of the Brazilian legal-political situation with that of other nations, primarily European ones, was used. . In view of the changes faced on European soil, and the emergence of the juspositivist movement, the Brazilian tax legal system starts to be analyzed, under the positivist influences, which led, after some attempts to correct traditional national legal-political problems, such as income distribution, disparate taxation criteria, among others, the need for codification to emerge.

KEYWORDS: Brazilian Tax System; Brasil Colônia; European Systematic Ideology; Juspositivist movement; Tax coding.

\section{INTRODUÇÃO}

A funcionalidade do Sistema Tributário brasileiro, costumeiramente condicionada à um conjunto de regras que obedecem a uma ordem sagrada e inafastável, pode ser comparada à organização de formas e cores das estampilhas, alegorias, fantasias, ritmos e coreografias do Carnaval, festa popular que se tornou uma das principais representações do Brasil mundo afora. Foi fazendo uma analogia ao Carnaval brasileiro que, em meados de 1989, com a publicação de sua obra Carnaval Tributário, Alfredo Augusto Becker, com persuasão que lhe

\footnotetext{
${ }^{1}$ Pós-doutorando em Direito Constitucional pela Universidade de Fortaleza (UNIFOR/CE). Doutor em Direito Constitucional Público e Teoria Política, pela Universidade de Fortaleza (UNIFOR/CE). Professor do Centro Universitário Fanor Wyden (UniFanor Wyden). E-mail: vicenteaugusto2@gmail.com.
} 
era peculiar, submeteu o Sistema Tributário nacional. Na década de 40, as diretrizes da Política Fiscal concentravam-se em disciplinar as estampilhas federais, estaduais e municipais no seu ritmo e com a tropicalidade das suas cores. Essas mesmas estampilhas deveriam obedecer a uma ordem de mutações, segundo a competência constitucional impositiva, a natureza e o valor do tributo, os dotes e a imaginação do artífice gravador da matriz da estampilha, entre outros. E, graças ao colorido e ao formato diferenciado das estampilhas, é que o Sistema Tributário, para Becker, era um Carnaval. Somente havia muita confusão, muito papel colorido, mas, mesmo assim, era divertido. A festa, entretanto, não parou por ali. Em 1963, o Supremo Tribunal Federal, em Tribunal Pleno, decidiu a natureza dos empréstimos compulsórios como tributos, mediante uma votação esdrúxula de dez votos a um, criando a possibilidade, para o autor, de que se mascarassem diversos tributos na forma de "empréstimos".

Nesse contexto, explanou Becker, estava formado a alegoria dos "Unidos da Vila Federal", sendo o Presidente da República e o seu Ministro da Fazenda aqueles que abrirão as alas, lançando confetes e serpentinas dos bolsos vazios e das tripas dos contribuintes, respectivamente, em busca do prêmio, por unanimidade, da "Fraude contra o Contribuinte". Com o crescimento abrupto de decisões tributárias controvérsias, tanto na seara judicial, quanto na administrativa, a posição do ordenamento jurídico tributário e, mais especificamente, do sistema tributário, de forma geral, foram questionados. O presente trabalho tem por objetivo a investigação da gênese do conceito de "sistema tributário brasileiro", na qual se utilizou, como corte epistemológico, de uma abordagem comparativa da situação jurídico-política brasileira para com a das demais nações, primordialmente as europeias. Diante das modificações enfrentadas em solo europeu, e o surgimento do movimento juspositivista, passa-se a analisar o ordenamento jurídico brasileiro, e, mais especificamente, o sistema jurídico tributário, sob as influências positivistas, que levaram, após algumas tentativas de correção de tradicionais problemas jurídico-políticos nacionais, como a distribuição de renda, critérios díspares de tributação, entre outros, a emergir a necessidade de uma codificação. Para tanto, abordar-se-á a temática por intermédio de um método lógico-dedutivo, pautado em análise doutrinária e legal, com ênfase na resolução da problemática proposta.

\section{A influência das ideias jurídicas sistemáticas europeias na doutrina jurídico-brasileira}


A formação da cultura jurídica brasileira não se sucedeu de maneira autônoma, e foi influenciada, em muito, pelas instituições e ideias apresentadas, debatidas e defendidas na Europa. Essa medida pode ser verificada, de forma explícita, principalmente na construção dos institutos de direito privado e, de maneira - ainda que, à primeira análise, tímida - na configuração dos institutos de direito público. Em razão da ausência de uma identidade nacional, vez que a nacionalidade brasileira ainda era incipiente, e passava por constantes modificações em sua estrutura basilar pelas peculiaridades da conjuntura socioeconômica vivenciada pela futura nação, desenvolveu-se o Direito brasileiro por intermédio de importações jurídico-doutrinárias e eventuais adaptações do Direito europeu. Por esse motivo, é possível afirmar-se que o Direito brasileiro é considerado como de ordem jurídica secundária, e assimilava a influência dos ordenamentos exportadores de Direito por intermédio da colonização portuguesa - entre os anos de 1500 até 1822 - ou por recepções voluntárias de instituições jurídicas singulares - após 1822 e até a instauração da República.

Por via de consequência, o ordenamento jurídico brasileiro foi, por diversas oportunidades, tratado como uma síntese de ordenamentos e direitos europeus, e, ainda que apresentasse determinados institutos, criados a partir das características peculiares do solo brasileiro, ainda trazia ensinamentos pautados na vulgarização das tendências jurídicas europeias. Foram as influências externas, ainda que não tenham sido efetuadas de forma homogênea, muito menos constante, e tampouco simultânea, no tempo e no espaço, que moldaram o Direito brasileiro em seus primórdios. Em razão disso, a assimilação dos institutos e ideias europeias, por sua vez, não se fez sempre de maneira integral, com a ocorrência, em diversos casos, talvez na sua maioria, de um processo de transmutação que, em determinadas situações, tornou praticamente irreconhecíveis algumas instituições estrangeiras que aqui se aplicavam. Essa, por oportuno, é uma característica marcante do Direito brasileiro: importação, adaptação e transmutação constante para suas particularidades ou ideais.

Os juristas brasileiros, de forma tradicional, recorreram - ainda o fazem, e talvez nunca deixem de fazê-lo - ao estudo e ao ensino do Direito estrangeiro (VALLADÃO, 1971, p. 321), e, inclusive, prática que perpetuou instituições, diretrizes, princípios, regras e comportamentos, sob diversas formas e modelos, que atravessaram o tempo, e perpassaram desde a Colônia, Império, República "Velha" e República "Nova”, até a contemporaneidade (FERREIRA, 1986, p. 20). Pode-se afirmar que ocorreu, em vários momentos, um 
fenômeno próximo ao do mimetismo (TARDE, 1904, p. 20-21), da imitação, por intermédio do qual, somente após um período de adaptação ou ajustamento às condições locais brasileiras, é que os modelos transplantados do Direito europeu e norte-americano, entre tantos outros, puderam produzir efeitos próximos aos desejados ${ }^{2}$. Citem-se, como exemplos, sem prejuízo de outros tantos, o estabelecimento da enfiteuse, no Direito Civil; da federação, no Direito Constitucional; do habeas corpus, no Direito Processual Civil e no Direito Processual Penal (CAVALCANTI, 1980, p. 13-14). Inclusive, o Direito comparado tem sido utilizado, em várias oportunidades, como um modelo ideal, assemelhado a um parâmetro de atuação, em que se evidenciam as dificuldades de uma identificação ideal das instituições jurídicas que foram importadas no Brasil. Essa medida verifica-se na constituição das fontes, da natureza legislativa, na formação eminentemente europeia dos juristas nacionais; e até mesmo nos elementos centrais para o processo de Independência e, também, após ele.

A existência de uma experiência jurídica nacional passa, por muito, por alguns fatores jurídico-ideológicos relevantes, destacados, entre tantos outros, em razão das peculiaridades assumidas no caso brasileiro (TAVARES, 1990, p. 57). Mas é na incidência de outras imediações que é possível traçar um perfil da cultura jurídica nacional e da implementação do ideal sistemático no Brasil, vez que a construção da experiência jurídica brasileira apresenta mais uma experiência política e, em termos mais amplos, uma experiência cultural, inclusive em um período histórico em que restava ausente pensamentos de outras naturezas, como o filosófico (PAIM, 1984, p. 18). Primeiramente, por força da concretização cultural, pautada na existência de marcos nacionais, capazes de configurar complexos axiológicos singulares, bem como, em segundo lugar, por indicações mais teóricas, na efetiva presença de valores e de constantes axiológicas dentro de toda a experiência jurídica brasileira, principalmente quando consideradas as suas elaborações legislativas (SALDANHA, 1987, p. 55). Dentre as causas de ordem política que levaram à utilização, pelo Brasil, de uma experiência jurídico-ideológica estrangeira, pode ser apontado o início da nação enquanto colônia, fato este que introduziu em solo brasileiro uma série de instituições

\footnotetext{
${ }^{2}$ A análise aprofundada das razões pelas quais as nações em desenvolvimento sentem-se estimuladas a permitir a penetração do Direito estrangeiro, seja pelo mimetismo, seja pela atração exercida pelo elemento estrangeiro sobre os autóctones, foge aos objetivos do trabalho. Entretanto, por todos, cite-se, acerca do mimetismo, ainda que específico para a situação do direito privado: PAPACHRISTOS, Athanase C. La réception des droits privés étrangers comme phénomène de sociologie juridique. Paris: Librarie Générale de Droit et de Jurisprudence, 1975. E sobre os autócnes: CARBONNIER, Jean. Essais sur les lois. Paris: Répertoire du Notariat Defrénois, 1979.
} 
jurídicas portuguesas, e, consequentemente, forneceu as condições ideais para a inserção dos institutos jurídicos romano-germânicos, que já faziam parte do ordenamento jurídico português do período (TAVARES, 1990, p. 58). A influência dos ordenamentos jurídicos europeus fez-se presente, primordialmente, no direito privado, e, notadamente, o papel das instituições jurídicas brasileiras, pautadas por influência romano-germânica, foi fundamental para o alcance de modificações substanciais no país, como na Independência. Essa medida é evidenciada pela permanência das Ordenações portuguesas, que continuaram em vigor até meados do início dos anos de 1900, até a consolidação do Código Civil brasileiro, de 1916.

Foi a influência do Direito europeu da Península Ibérica, ainda com Portugal enquanto nação secundária, formado pelo desdobramento de um dos reinos espanhóis, que influenciou a gênese do ordenamento jurídico brasileiro. O Direito herdado de Portugal, inclusive aquele presente na regulamentação burocrática das Ordenações do Reino, foi acrescido de uma incipiente legislação extravagante, quase como um Direito de circunstância (MENDONÇA, 2004, p. 18), aditada à legislação lusitana conforme as leis gerais metropolitanas codificadas nas Ordenações, e de forma influência franco-inglesa ${ }^{3}$. Da mesma forma, a influência romano-germânica se fez presente no direito público, vez que deu origem a inúmeros fenômenos de recepções de princípios e institutos estrangeiros, ainda que essas recepções não pudessem ser observadas facilmente. Portanto, é possível afirmar que não se desconhece a influência das ideias liberais britânicas - inglesas e escocesas - e francesas na gênese do Estado brasileiro ${ }^{4}$ - amplificadas, por muito, pelas divulgações não apenas daqueles que haviam cursado Direito ou ciências semelhantes em universidades europeias, mas, também, por ávidos e habituais leitores de obras estrangeiras que já se encontravam em

\footnotetext{
${ }^{3}$ As causas de afinidade doutrinária entre Brasil, França e Inglaterra é decorrente de uma oportunidade histórica, que, em muito, favoreceu a aproximação e difusão das ideias franco-inglesas, particularmente no período anterior à Independência. Com a invasão de Portugal pelas tropas de Napoleão Bonaparte, a Corte portuguesa, já transferida para o Brasil, estreitou os laços comerciais e políticos com a Inglaterra. Dessa forma, foi natural a incidência do Direito britânico em solo brasileiro. Enquanto isso, a França, cujas relações já eram relativamente próximas, até o governo de Napoleão Bonaparte, foram retomadas em 1816, e, desde então, apenas fortaleceramse. Entretanto, as influências da Revolução Francesa já haviam se estabelecido no Brasil. Conf. TAVARES, Ana Lucia de Lyra. O Direito comparado na história do sistema jurídico brasileiro. Revista de Ciência Política, Rio de Janeiro, v. 33, n. 1, p.55-90, nov. 1989/jan. 1990, p. 58.

${ }^{4}$ Ressalte-se o posicionamento de Louis-François Tollenare, historiador francês, que ficara surpreso de ter encontrado uma vasta influência de obras francesas, bem como dos textos constitucionais de 1791, 1793 e 1795 sobre os revolucionários de Pernambuco, em 1817. Essa medida comprova que, desde períodos remotos, o Direito brasileiro consubstanciou-se de fontes europeias francesas, por exemplo. Conf. TOLLENARE, LouisFrançois. Notas dominicais tomadas durante uma viagem em Portugal e no Brasil em 1816, 1817 e 1818. Salvador: Livraria Progresso Editora, 1956, p. 256 e ss. Ver, também: MOTA, Carlos Guilherme. Presença francesa em Recife, em 1817. Caravelle. Cahiers du monde hispanique et luso-brésilien, Paris, v. 15, p.47-56, 1970.
} 
solo nacional - mas a participação do arcabouço ideológico romano-germânico foi fundamental para o que se tornou a configuração jurídico-brasileira nos anos seguintes.

Por sua vez, dentre as causas de ordem socioculturais, podem ser apontadas as pretensões e ideologias das elites intelectuais e políticas no Brasil, que se mantiveram, por um longo período, com suas atenções direcionadas para os acontecimentos jurídico-ideológicos na Europa e, também, nos Estados Unidos da América. Essa medida foi essencial para a estimulação de importações jurídicas específicas, e que, com certa frequência, não atendiam às necessidades locais. Assim, efetuava-se a distorção do modelo transplantado, para a obtenção de efeitos diversos daqueles alcançados nos países de origem. Podem ser citados, sem prejuízo de outros, o caso da adoção da República e do Federalismo no Brasil, bem como a adoção do modelo de jurisdição norte-americano. Diante da prática inerente do Direito brasileiro em assimilar a influência de doutrinas jurídico-políticas europeias, far-se-ia natural a incidência do viés sistemático em solo brasileiro. Porém, quando se trata de uma análise da gênese do ideal sistemático no Brasil, verifica-se que, ainda que tenha alcançado singela popularidade no Direito europeu - principalmente após a instauração da doutrina da filosofia prática de Thomas Hobbes, até meados do século XVIII, com o movimento iluminista, conforme ressaltado anteriormente, o Direito brasileiro, de forma aparente, não sofreu de suas implicações de imediato. Pelo contrário, o Direito brasileiro demonstrou-se completamente desconectado, por diversas décadas, do ideal de sistema utilizado nas diversas nações europeias. Tanto que, nesse ínterim, o termo "sistema" era associado a um conjunto de leis, normas ou disposições jurídicas, ou, ainda, a um contexto amplo de ideias - quando, por exemplo, considerava-se sistema um aglomerado organicista de disposições jurídicas conectadas. Mas, em nenhum momento no período que compreende a fase pré-colonial, até o estabelecimento da República "Velha", verificou-se a aplicação da doutrina europeia do viés sistemático de forma efetiva.

Ressalte-se, por oportuno, que na seara tributária, em particular, algumas caraterísticas apresentadas pelo ordenamento jurídico brasileiro, bem como por seus atores, são fundamentais para que se possa compreender os fenômenos inerentes à sua formação e funcionamento, e, ainda, fornecem substrato para a verificação de uma - pouco linear distribuição evolutiva. No decorrer de mais de três séculos de construção jurídico-doutrinária, o sistema tributário brasileiro demonstrou-se influenciado pelas seguintes caracterizações, relacionadas entre si: a) marcado pela influência direta - e também, indireta, apenas que em 
menor escala - da forma de governo adotada no País; b) vinculado diretamente à forma de governo utilizada, com a busca constante por uma distribuição de receitas mais efetiva; c) uma preocupação - por vezes exagerada - com a legitimação do sistema e a sua configuração pautada por fundamento legal, no qual se destaca a organização do sistema - quase sempre com retorno às suas raízes constitucionais; d) a determinação de princípios, regras e conceitos específicos do sistema, com o condicionamento dos institutos inerentes ao Direito Tributário brasileiro; e e) o retardamento da incidência da ideologia sistemática europeia no Brasil, mas seguida, por alguns momentos, quase à risca e contra as intrínsecas delimitações do próprio ordenamento jurídico pátrio. Independente do período analisado, verificar-se-á, em algum momento, ou em pouca, mas persistente medida, o sistema tributário brasileiro e sua associação a essas características, dependentes de si mesmas de forma ideológica ou fática, mas independentes diante da construção jurídico-política de seu tempo. Mesmo porque, paralelamente a essas características, os elementos história, sistema e tempo são indissociáveis.

\section{$2 \mathrm{O}$ período colonial (1500-1822) e o retardamento da incidência sistemática no Brasil}

O período pré-colonial, compreendido entre os anos 1500 até 1530, corresponde ao tempo em que Portugal não povoou com europeus as terras conquistadas, por considerar bastante, à época, a mera utilização do território, mas, ainda, sem qualquer processo de colonização de fato. A Coroa portuguesa não optou pela colonização naquele momento, vez que se concentrava na exploração do comércio pelas rotas marítimas indianas. Essa medida, por conseguinte, atendia aos seus interesses mercantilistas (ANGELOZZI, 2009, p. 25-26). Nos primeiros 30 (trinta) anos desde a chegada daqueles que viriam a ser os colonizadores do território brasileiro, a preocupação da Coroa portuguesa estava em manter a posse das terras "encontradas" - representada pela instalação de diversas feitorias, que marcavam o reconhecimento dessas posses - e, também, pelas incursões pela selva, para conhecer as potencialidades da "Terra de Santa Cruz" (AMED; NEGREIROS, 2000, p. 24). Sendo assim, as novas terras serviam para fins de natureza comercial, por intermédio do monopólio real que não era exercido de forma direta, mas por concessões. A aliança entre a atividade econômica do rei e os comerciantes envolvia a utilização de forças militares armadas na exploração mercantil, e a concessão era realizada por uma "carta de privilégio", que seguia os antigos costumes portugueses (MORAES, 1996, p. 109). 
A estrutura administrativa básica do Brasil pré-colonial era formada, portanto, do rei, em primeiro lugar, como concessionário ou garantidor da integridade comercial, que o faria com suas formas civis de controle e território, e, finalmente, do outro lado, os contratados, armadores de naus, vinculados ao financiadores europeus - que, por sua vez, eram interessados em redistribuir mercadorias (FAORO, 2001, p. 124-125). A atuação se daria pela feitoria realizada. O sistema de administração por feitorias era formado por simples abrigos, que serviam para reunião e proteção das diferentes mercadorias que aguardavam o transporte, assemelhados, em muito, a um sistema de administração utilizado na Europa em tempos medievais, quase vinculados ao feudalismo. Apesar de simples, o sistema de feitorias tornouse um elemento problemático para a Coroa portuguesa, vez que demonstraram, desde logo, um ponto vicioso, incontrolável e precário, proveniente da instabilidade dos habitantes nativos da terra, que não se submetiam à escravidão ou a qualquer forma de obediência ou tratado. A insuficiência do sistema de feitorias determinou que o governo português passasse a adotar uma forma mista, com armada de conteúdo guarda-costas e exploradora (MENDONÇA, 2004, p. 18). O Brasil não representava qualquer interesse à Coroa portuguesa naquele momento. Não apresentava um número de metais preciosos - amoedáveis e fundamentais para trocas - e mercadorias suficientes para serem distribuídas por toda a Europa. Ainda assim, a presença de uma população indígena - notável pela ausência da noção de acumulação de riqueza e sem a preocupação com a produção de excedentes - era mais um elemento dificultador, apesar de representarem, para alguns, oportunidade perfeita de exercício da catequese, com disseminação do cristianismo em terras brasileiras (BALTHAZAR, 2005, p. 32). Entretanto, o descobrimento do pau-brasil, árvore de onde se extrai uma madeira fornecedora de tinta avermelhada, muito utilizada, à época, para se tingir tecido e de custo muito elevado, logo após as primeiras incursões de exploração do potencial exercido pelas terras brasileiras, fez com que o interesse primordial da Coroa portuguesa fosse relativamente modificado (AMED; NEGREIROS, 2000, p. 25).

Assim, todos os interessados na realização da atividade deveriam pagar ao Rei português uma determinada contraprestação em dinheiro ou em espécie, bem como deveriam cumprir uma série de outras obrigações. Em troca da exploração do produto, exigia-se do concessionário que erguesse as primeiras fortificações ao longo da costa iniciasse o processo de colonização do território e que pagasse o denominado Quinto - quinta parte do produto da 
venda da madeira ${ }^{5}$ - à detentora do monopólio. Esse foi, indiretamente, o primeiro tributo instituído no Brasil. Entretanto, por ser um tributo pago diretamente à Coroa portuguesa, bem como não foi criado a partir da chegada dos portugueses no Brasil - a previsão já existia na legislação de Portugal há alguns anos - não é possível afirmar que existia, em território nacional, um sistema tributário próprio ou, muito menos, qualquer organização sistemática nesse sentido. No caso, as práticas apenas foram importadas da legislação portuguesa até as novas terras, sem qualquer adaptação à realidade em que foram colocadas. Na verdade, apesar do conjunto tributário - mesmo que em viés precário ou reduzido, e já adaptado à realidade encontrada naquela que viria a ser mais uma das colônias portuguesas - oriundo do Direito português, não existia qualquer organização ou estruturação efetiva. Não existia, por via de consequência, nenhum sistema tributário, sob a ótica jurídica (MORAES, 1996, p. 109) . Pode-se afirmar, portanto, que o período pré-colonial, em razão do desinteresse da Coroa portuguesa em efetivar a colonização, bem como em consequência da ausência do poder português em solo brasileiro, não permitiu o desenvolvimento de atividades econômicas significativas. E, ainda, reiterou o caráter de mera feitoria do Brasil perante Portugal, vez que não passava de mais um território de passagem e de parada das embarcações lusitanas que se direcionavam às Índias ou ao Oriente da Europa.

O sistema de feitorias adotado no Brasil não impediu, inclusive, as incursões francesas na costa, desde 1504. Foi no sentido de eliminar a incidência francesa no território vez que já fundava feitorias nas costas do Brasil - e a competição espanhola pelo sul do continente americano, que D. João III, então rei de Portugal, expediu três cartas-de-poderes em favor de Martim Afonso de Sousa, que comandou uma expedição para a eliminação das ameaças às posses portuguesas. Essa medida é considerada, por muitos, como o início da história administrativa no Brasil, e que foi fundamental para o estabelecimento do sistema tributário brasileiro no país (MENDONÇA, 2004, p. 21). As três cartas-de-poderes concediam a Martim Afonso de Sousa o título de capitão-mor da Armada que enviou ao Brasil, bem como lhe concedia todas as terras que encontrasse durante o exercício de suas funções. Traziam os documentos, ainda, o regimento de governo que deveria ser adotado por Martim Afonso de Sousa em terras brasileiras (TAPAJÓS, 1983, p. 149-150).

\footnotetext{
${ }^{5} \mathrm{O}$ Quinto já era conhecido como um tributo que se pagava à Coroa portuguesa por todas as tomadas realizadas, quais sejam, de tesouros e descobertas, consistentes na quinta parte do tomado, inventado ou descoberto. Conf. FERREIRA, Waldemar Martins. História do Direito brasileiro. São Paulo: Max Limonad, 1956, t. IV, p. 135.
} 
Entretanto, a frequência dos franceses no litoral brasileiro, a carência de um sistema de administração colonial - em que o estilo administrativo permanecia vinculado ao temperamento pessoal dos governadores; a descontinuidade geográfica; o tratamento cruel dado aos indígenas; a ausência de condições demográficas favoráveis; e a evolução do comércio particular competitivo para o comércio estatizante e monopolista levaram D. João III a intensificar a ocupação do Brasil (MORAES, 1996, p. 110). O receio de perder a posse das novas terras para outros Estados europeus, o término do monopólio do comércio de especiarias com as Índias, bem como as dificuldades financeiras que atravessava Portugal, fizeram com que se implementasse um regime de colonização no Brasil, desde que não fossem requeridos muitos recursos públicos para tanto. A solução encontrada pela Coroa Portuguesa foi a implementação do sistema de capitanias hereditárias, que já eram utilizadas com sucesso em outras possessões portuguesas - Açores e Madeira. A atividade econômica escolhida para ser exercida pela colônia, com vistas a gerar lucros e que compensasse as despesas de transporte, ainda nos primórdios da Industrialização europeia, foi a da produção de cana-de-açúcar.

O sistema de capitanias consistia em conceder lotes de terra a particulares denominados donatários, com direitos de sucessão, por intermédio de "cartas de doação", e as "cartas de foral", que, além de preverem a povoação da colônia, determinavam direitos, foros, tributos e demais coisas que se pagariam ao Rei, ao Capitão-Mor - ainda encarregado de arrecadar tributos - e ao governador. A colonização do Brasil resultou, assim, da associação das iniciativas públicas e particulares. As capitanias hereditárias representaram uma medida administrativa de circunstância, que abriu uma ampla exceção no processo de centralização decorrente da Lei Mental ${ }^{6}$ portuguesa, e tinha uma aparência de cunho feudal. Tratava-se de uma porção de terra dividida em "senhorios dentro do senhorio do Estado" (MENDONÇA, 2008, p. 506), as quais, analisadas sob a maneira pela qual os donatários exerciam o domínio do solo, constata-se que sofriam diversas restrições, vez que a doação das sesmarias era uma limitação, e não uma faculdade. As limitações estabelecidas aos donatários eram de tal monta,

\footnotetext{
${ }^{6}$ A Lei Mental é utilizada como designação para uma lei que foi editada por D. Duarte I, em 8 de abril de 1434 , durante as Cortes que tiveram lugar em Santarém, e que tinha por objetivo coibir a frequência das doações de bens da Coroa compensatórias aos serviços prestados. D. João I, com o concurso do jurista João das Regras, imaginara uma lei que disciplinasse os direitos dos donatários aos bens doados e a forma de sucessão. Mas não a expediu. Promulgou-a D. Duarte I naquela data, que restou conhecida como Lei Mental, porque seu pai a tivera em mente, mas não a executou de fato. Tratava-se mais de um plano político - integrado ao sistema de centralização, reitere-se - do que uma lei civil. Conf. AVELAR, Hélio Alcântara. História administrativa e econômica do Brasil. Rio de Janeiro: MEC/Fename, 1976.
} 
que poderiam implicar, inclusive, na reversão da capitania ao Reino, se não fossem respeitadas, tal como, efetivamente ocorreu, nos casos de abandono. Os donatários, apesar das grandes concessões, não passavam de delegados régios. A centralização políticoadministrativa do governo exercido na colônia é fundamental para a configuração dos tributos que, porventura, fossem cobrados naquela terra. Surge, dessa forma, o primeiro viés de divisão e distribuição de receitas.

A centralização do poder, focado no repasse das maiores quantias para a Metrópole, bem como a consideração de todo esse patrimônio como de sua propriedade, foram fatores determinantes para uma dependência jurídico-administrativa das capitanias para com o Rei e o Capitão-Mor, que eram intimamente conectadas a fins de apuração, coleta e partilha das rendas públicas (FERREIRA, 1962, p. 170). Os servidores da Coroa guardavam o produto da arrecadação fiscal em armazéns, concediam ao donatário da capitania sua parte e enviavam salvo para Portugal. Inexistia qualquer organização fiscal no período, e a arrecadação e fiscalização dos tributos eram realizadas pelos servidores especiais da Coroa portuguesa, denominados "rendeiros", e pelos seus auxiliares, almoxarifes - mais tarde denominados contadores e vedores. A autoridade desses agentes era evidente, e permitia-lhes multar, executar cobranças ou condenar infratores da legislação fiscal portuguesa, bem como lançar os tributos e determinar a forma e a época da arrecadação de cada qual (HUGON, 1945, p. 157). Esses tributos eram pagos, geralmente, in natura - em espécie, e não havia qualquer preocupação em elaborar planos orçamentários. O pagamento, portanto, era feito em um desorganizado método de arrecadação, realizado por representantes da Coroa portuguesa. Nesse contexto, é possível afirmar que muitos tributos foram transferidos e adaptados da legislação lusitana para o Brasil colonial, sem quaisquer distinções, no que resta configurada mais uma ausência de um sistema tributário brasileiro (MORAES, 1996, p. 111).

Em 1548, ao reconhecer a ineficácia ou o fracasso do sistema de capitanias hereditárias implementado, D. João III o substituiu por um novo sistema, ainda mais centralizador no poder, de direção única, pautado no representante direto de Portugal, que era o Governador-Geral. No dia 17 de dezembro de 1548, D. João III expediu o Regimento de Tomé de Sousa - considerado o primeiro Estatuto Fundamental do Brasil - por intermédio do qual restou instituído o Governo-Geral, e que, claramente, estabeleceu a razão da medida com a carta régia de 7 de janeiro de 1549, a qual nomeou Tomé de Sousa para cargos de capitão da povoação e terras da dita baía de Todos os Santos, e de Governador-Geral da referida 
capitania e das outras, bem como das terras da costa do "dito Brasil" por tempo de três anos e com 400.000 (quatrocentos mil) reais de ordenado em cada ano. O regimento concedido dado a Tomé de Sousa estabeleceu as bases do sistema do Governo-Geral, e perdurou até meados de 1677, quando foi conferido ao governador Roque da Costa Barreto um novo regimento. Tanto pelo regimento expedido em favor de Roque da Costa Barreto, como pelo Regimento do Estado do Maranhão, de 1621, e pelas Ordenações do Reino, nos casos expressamente regulados, bem como pelas chamadas leis extravagantes, regeu-se a ordem civil e administrativa da colônia até o ano de 1763, quando foi expedido novo regimento aos vicereis no Brasil. E a tributação não escapou dessa medida (SOUSA, 1954, p. 45-48). O Governo-Geral não foi estabelecido para substituir o sistema de capitanias hereditárias, mas para corrigir o sistema já instalado e suprir a falta - desde muito verificada - de um centro de unidade administrativa, que se revelou gradual, crescente e constante, até o seu desaparecimento. A implementação das medidas adotadas pelo Governo-Geral trouxe, ainda, outras consequências para a continuidade das capitanias hereditárias: a derrogação de todas as disposições contrárias à carta régia instituidora do novo sistema; a jurisdição plena atribuída aos capitães-mores, no âmbito cível, administrativo e criminal, entre outras (MENDONÇA, 2008, p. 506).

A configuração do governo colonial modificou-se mais uma vez, e, além dos capitães-mores e o Rei, surgiram mais duas instâncias judiciais: a do ouvidor-geral e a do Governador-Geral. A Carta Régia tratava, de maneira geral, da defesa da costa, das capitanias e da situação dos habitantes nativos, bem como estabelecia o regime das sesmarias e do estabelecimento de fortalezas e povoação que sediariam o governo. Apresentava, ainda, disposições sobre o pau-tinta; o devassamento do sertão; as restrições ao luxo; os engenhos; o comércio; a movimentação dos colonos; os preços; os funcionários; as rendas e direitos; as armas; o regime de visitas de correição do Governador-Geral; a concessão de títulos e prêmios por serviços prestados, entre outras (TAPAJÓS, 1983, p. 203-214). O Governo-Geral estava constituído de quatro órgãos superiores, com suas funções e atribuições independentes, mas vinculadas entre si: Governador-Geral; Ouvidor-Geral; Capitão-Mor da Costa e Provedor-Mor da Real Fazenda ${ }^{7}$. Este último, em particular, dentre outras atribuições, detinha

\footnotetext{
${ }^{7}$ Para Rubens Gomes de Sousa, a centralização político-administrativa da colônia é considerado um indício do estabelecimento de um "sistema" tributário brasileiro federal (ou nacional, vez ausente, ainda, o regime federativo no País). De qualquer forma, a divisão e a distribuição de receitas também indicariam, em certa medida, um direcionamento para uma tendência nacional do viés tributário, e estritamente vinculada à forma de
} 
a de realizar a superintendência e a fiscalização dos negócios da Real Fazenda, inclusive para zelar pela arrecadação do dinheiro público, com a concessão de necessárias providências sobre as alfândegas e as "casas de contos" - local em que os contadores pagavam, recebiam e verificavam as contas da população (HUGN, 1945, p. 158). O período do Governo-Geral, até 1603, não apresentou mudanças significativas na ordem jurídico-tributária da colônia. Os poderes dos Governadores eram os mesmos, e o Brasil permanecia dividido em capitanias, mas, agora, em uma subdivisão entre capitanias reais e hereditárias. Eram consideradas reais aquelas em que os titulares eram denominados capitães-mores. Dividiam-se em comarcas, que, por sua vez, subdividiam-se em termos, e que eram sediadas nas vilas e cidades (MORAES, 1996, p. 112).

No período, existiam apenas duas cidades reais - Salvador e Rio de Janeiro - que, por sua vez, eram divididas em freguesias. Havia uma certa confusão entre as divisões civis e eclesiásticas, mas, de um modo geral, as funções judiciárias, civis e militares e eclesiásticas eram distribuídas pela mesma circunscrição territorial, distinguindo-se pela natureza dos seus agentes (AVELAR, 1976, p. 77-79). Deve-se ressaltar que D. Sebastião I, sucessor de D. João III, desaparece, em 1578, sem deixar descendentes na batalha de Alcácer-Quibir, enquanto enfrentava os mouros, e essa medida encerra a Dinastia de Aviz. Foi nomeado ao trono o Cardeal D. Henrique, entre 60 e 70 (sessenta e setenta) anos de idade. Morto D. Henrique, em 1580, seguiu-se uma crise de sucessão, com três netos de D. Manuel I, de Portugal a reivindicar o trono: D. Catarina, infanta de Portugal (futura mãe do rei português D. João IV), duquesa de Bragança; D. António, Prior do Crato; e Filipe II, rei da Espanha. Como apoio da nobreza portuguesa, que mantinha estreitas relações com a Espanha, bem como da burguesia portuguesa, que detinham expectativa de infiltrar-se no México e no Peru, regiões produtoras de metais preciosos (ANGELOZZI, 2009, p. 34). Ao superar a resistência da pequena burguesia dos cristãos-novos - que eram contrários ao fanatismo religioso - inclusive com relações próximas ao Tribunal do Santo Ofício da Inquisição - do pretendente ao trono, Filipe II, da Espanha, foi aclamado rei de Filipe I, de Portugal, e se iniciou um período de União Ibérica, entre as dinastias da Espanha e de Portugal, de 1581 a 1640 (ANGELOZZI, 2009, p. 34). Iniciava-se a Dinastia de Habsburgo. Nesse período, que compreendeu os reinados de

organização político-administrativa da colônia. Esse mesmo corte metodológico é utilizado pelo autor para a verificar de seus argumentos em períodos posteriores, ainda que sob a égide de textos constitucionais. Conf. SOUSA, Rubens Gomes de. O sistema tributário federal. Revista de Direito Administrativo, Rio de Janeiro, v. 72, p.1-22, jan./mar. 1963, p. 1-2. 
Filipe I de Portugal (Filipe II na Espanha, de 1580 a 1598); Filipe II de Portugal (Filipe III na Espanha, de 1598 a 1621) e Filipe III de Portugal (Filipe IV na Espanha, de 1621 a 1640), não se determinou a anexação de Portugal à Espanha, e não houve conquista, apenas reconhecimento de direitos sucessórios.

No âmbito político-administrativo, notabilizaram-se os regimentos e atos regimentais, documentos de ordem administrativa consubstanciados em textos como: Regimento do Desembargo do Paço, dos Sargentos-Mores das Ordenanças das Comarcas, das Terras Minerais do Brasil, do Novo Tribunal ou Conselho do Estado da Índia e Estados Ultramarinos, da Casa de Suplicação, do Pau-Brasil, da Relação da Casa do Brasil e ou da Bahia, normas regimentais referentes à liberdade dos Índios, do Governador-Geral Gaspar de Sousa, entre outros. Durante a União Ibérica, uniram-se as áreas já colonizadas. O Estado do Brasil continuou colônia de Portugal e, sob o viés jurídico, a União Ibérica não afetou sobremaneira a situação portuguesa nem a brasileira e de outros domínios, mas o complexo conjuntural resultante da união dinástica modificou sensivelmente a Colônia, tanto de forma favorável como desfavorável (RIBEIRO, 1983, p. 318). Ressalte-se, outrossim, que foi um período marcado por uma série de invasões ao território brasileiro, as quais notabilizaram-se por adicionarem práticas políticas, econômica e jurídicas relativamente diferenciadas. $\mathrm{O}$ período correspondente à União Ibérica perdurou até 1640, quando a burguesia e a aristocracia portuguesas, descontentes com o domínio espanhol e com o reinado do rei Filipe III de Portugal - rei Filipe IV na Espanha. Para tanto, decidem restaurar a independência do país, e escolheram D. João, filho de Teodósio II, o sétimo Duque da Casa de Bragança, para assumir o trono português. O novo rei assumiu o trono sob o título de D. João IV, e, como um de seus primeiros atos, instituiu a renovação da vigência das Ordenações Filipinas em Portugal e nas suas colônias (ANGELOZZI, 2009, p. 45).

A restauração portuguesa coincidiu com a divisão das duas coroas, provocada pelo enfraquecimento do império filipino e o consequente fim da preponderância espanhola. Da restauração a meados do século XVIII, houve a consolidação do poder bragantino, no período de 1640 a 1698; a transição para o absolutismo de 1698 a 1706, que compreendeu a segunda fase de D. Pedro II de Portugal, a partir da convocação das cortes, de 1698, e a administração absolutista de D. João V, de 1706 a 1750. Na consolidação do poder da Dinastia dos Bragança, a política administrativa interna assinalou-se na metrópole, pela consulta às Cortes e nos senhorios, pela subordinação da administração colonial ao Conselho Ultramarino. A 
gestão externa caracterizou-se pela política de aliança com os rivais da Espanha e da guerra contra esta. Ao mesmo tempo, o Brasil ainda conhecia as Ordenações Filipinas, conjunto de diretrizes que substituiu as Ordenações Manuelinas. As Ordenações Filipinas foram sancionadas por Filipe I em 1595, mas só ganharam caráter de aplicação efetiva quando da realização de sua impressão, em 1603, já durante o reinado de Filipe II, de Portugal.

As Ordenações Filipinas apresentaram estrutura semelhante àquela utilizada nas Ordenações Manuelinas $^{8}$ - que, por sua vez, eram apenas as Ordenações Afonsinas reescritas - e detinham diretrizes de caráter tradicionalista, nas quais se promovia a reforma dentro de um viés que agradasse o povo português. Ressalte-se que as Ordenações Manuelinas sofreram, em muito, influência dos posicionamentos adotados por jurisconsultos portugueses, influenciados pelos ideais jurídico-filosóficos humanistas de Jacques Cujas, medida que favoreceu, guardadas as devidas proporções, ao que se poderia denominar como um simulacro de codificação (ALMEIDA, 2003, p. 56). O Direito luso-brasileiro passou a defender a lei como única fonte jurídica, vez que, além de ser considerada expressão da razão e, por isso, geral e abstrata, era tida segura, certa e clara e constituía um instrumento poderoso de transformação social. Afastou-se, portanto, o costume enquanto fonte primordial do exercício jurídico, por ser incerto e comprometido com o passado que urge transformar. A crença na omnipotência da razão - de forte viés humanístico da escola de Jacques Cujas, mas, também, com toques iluministas - justifica o afastamento dos posicionamentos adotados na medieval Escola dos Glosadores ${ }^{9}$, do romano Acúrsio, e das opiniões dos italianos Bártolo de Sassoferrato, Baldo dos Ubaldi, entre outros, porque eram consideradam probabilidades, e a razão pensa que tinha acesso à verdade. Deve-se ressaltar, ainda, que se afirmou no período o

\footnotetext{
${ }^{8}$ Para Fernando Whitaker da Cunha, as Ordenações Manuelinas contribuíram para uma posterior consciência codificadora - como como uma necrópole de preceitos, mas como um organismo vivo - que foi impulsionada pelo constitucionalismo, movimento revelador da urgência de constituições escritas, ainda que não se confunda com a codificação ou dela necessite para fins de complementaridade - como se fossem uma fórmula. Assim, pode haver a Constituição sem os Códigos, como no caso da Inglaterra e da Nova Zelândia. Conf. CUNHA, Fernando Whitaker da. O Direito português em 1500. Revista da EMERJ, Rio de Janeiro, v. 3, n. 10, 2000.

9 A Escola dos Glosadores, também denominada Escola de Bolonha, tinha como pressuposto geral as três principais representações da assimilação cultural romano-germânica, que seguiam uma proposta de reconfiguração social, já que a civilização urbana e racional latina, pautada na administração e na jurisprudência sistematizada, ainda que em seu sentido amplo, seria substituída por uma sociedade descentralizada politicamente, com a defesa do relativismo e do pluralismo jurídico: a herança cultural e administrativa da Antiguidade tardia, o poder universal da Igreja remanescente e a instituição do ensino escolar. Conf. WIEACKER, Franz. A History of Private Law in Europe: with particular reference to Germany. Oxford: Clarendon Press, 1996.
} 
Direito natural, e submeteu-se o direito romano ao crivo da razão, pelo qual só passa o direito do usus modernus pandectarum.

Especificamente no Direito Criminal e no Direito Processual Criminal, impôs-se a Escola Culta de Jurisprudência, com o Humanitarismo como valor notável. Assim, a justificação escolástica da pena - como expiação - é substituída pelas ideias de necessidade e utilidade com expressão na prevenção de todos, enquanto prevenção geral, e do próprio delinquente, enquanto prevenção especial. As penas corporais são substituídas pela pena de prisão, e defende-se a ideia de proporcionalidade da pena à gravidade do delito. E o respeito pela dignidade humana justifica os princípios in dubio pro reo e nullum crimen sine lege e determina a estrutura acusatória do processo criminal. Com base na teoria do contrato social, considera-se que a pena de morte não é necessária nem justa. E combate-se a tortura porque leva à condenação de inocentes débeis e à absolvição de celerados fortes. $\mathrm{O}$ cenário de modificação jurídica do Direito luso-brasileiro permitiu que as Ordenações Filipinas tivessem relativa longevidade, primordialmente porque cultura jurídica portuguesa - que, nesse ínterim, constituída um mesmo e único tronco com relação ao Direito brasileiro - e, depois da Independência, também a cultura brasileira, sofreram grandes e significativos impactos, provenientes do racionalismo humanístico renascentista e do Iluminismo, que tornaram a aplicação dessa antiga legislação algo mais permeável aos novos tempos.

A morte de D. João V, em 1750, possibilitou a recomposição do governo português. D. José I assumiu o trono, e nele mereceu especial destaque a atuação de Sebastião José de Carvalho e Melo, o Conde de Oeiras, posteriormente conhecido como o Marquês de Pombal, comandante do Gabinete Português de 1750 a 1777, e que muito influenciou o Brasil no século XVIII, período em que se verificou a uniformização dos padrões administrativos régios, e no qual acarretou-se a supressão das últimas capitanias hereditárias. A administração do Marquês de Pombal - considerado um ministro de cunho absolutista teocrático, no qual só há um poder, o do soberano - almejou revitalizar a autoridade do rei por intermédio da contenção da influência da nobreza, mas, ao mesmo tempo, resguardava a aristocracia enquanto instituição. O prestígio do poder real exigia sólida infraestrutura econômica, o que fez com que o Marquês de Pombal adotasse um paradoxal pragmatismo, com a edição de leis conforme as circunstâncias, e que procurava diminuir as perdas dos volumosos recursos que enviava para a Inglaterra. Assim, por consequência, estimulava, em alguns territórios, a liberdade mercantil e, em outros, praticava o mais estrito monopólio. A administração do 
Marquês de Pombal teve, ainda, cunho eminentemente fiscalista e unitária, na qual se expediu uma vasta legislação limitativa do crédito e da livre iniciativa, e que teve o mérito de assegurar organicidade e unidade à ação administrativa econômica. Sua política exterior foi pragmática e circunstancial, exemplificada pelo pedido de apoio diplomático-militar que fez à Inglaterra contra a Espanha.

Em 1762, a organização político-administrativa da colônia é relativamente modificada, com a nomeação do General Gomes Freire de Andrade como Vice-Rei do Brasil. Esse foi o início do período conhecido como governo dos Vice-Reis no País. Tratou-se de um período de elevada movimentação política, mas com poucos impactos na seara tributária. Os tributos, instituídos sem qualquer racionalidade - vez que se assemelhavam às derramas do Governo-Geral, na qual inexistia qualquer vinculação dos fatos geradores dos tributos a fato privado - continuavam exigidos de forma constante, com o mesmo sistema precário de fiscalização e arrecadação. Nesse mesmo período, outras espécies tributárias sugiram, e que muito alimentaram os cofres reais. Entretanto, a conjuntura político-administrativa da colônia ainda não era suficiente para prossecução dos fins alcançados pela Coroa portuguesa.

Por esse motivo, o Gabinete comandado pelo Marquês de Pombal realizou uma série de reformas político-administrativas que influenciaram, diretamente, o direito positivo lusobrasileiro, tanto no âmbito geral da ciência jurídica, quanto no ensino do direito. A primeira reforma foi consubstanciada na edição da denominada "Lei da Boa Razão", editada em 18 de agosto de 1769, e que é considerada como um marco no despotismo esclarecido português. Criada sob forte influência cultural iluminista e jusnaturalista, tinha por objetivo impor novos critérios de interpretação e integração das lacunas previstas nas leis. Para tanto, reprimia o abuso, até então vulgarizado, de recorrer aos textos jurídicos romanos ou a textos doutrinais em desprezo a disposições expressas do Direito português. Assim, tornava-se vedada a utilização, nas decisões judiciais, de textos romanos, ou a alegação de algum posicionamento doutrinário contrário às disposições previstas nas Ordenações, nos usos do reino ou nas leis pátrias (GOMES, 1958, p. 9-12). Somente no caso de lacunas é que se poderia recorrer aos textos romanos. Ressalte-se, assim, que o Direito romano ainda persistia enquanto utilização, mas adotou, no período, um viés subsidiário. Portanto, não era utilizado em si mesmo, mas sim por intermédio da razão jusnaturalista e da "boa razão". Conforme disposição expressa na lei, a "boa razão" deveria ser procurada nas "verdades essenciais, intrínsecas e inalteráveis, que a ética dos mesmos romanos havia estabelecido, e que o direito humano e divino 
formalizaram, para servirem de regras morais para o cristianismo", na qual é possível, ainda, buscar "outras regras, que, de unânime consentimento, estabeleceu o direito das gentes, para direção e governo de todas as nações civilizadas”, bem como, finalmente, seria possível procurar o "que se estabelece nas leis políticas, econômicas, mercantis e marítimas, que as nações cristãs têm promulgado". A "Lei da Boa Razão" determinava, ainda, que o direito canônico deixaria de ter aplicação subsidiária nos tribunais civis - fato este que, em parte, modificava a dinâmica das Ordenações - e, finalmente, bania a aplicação da Escola dos Glosadores, que eram tomadas como fontes subsidiárias pelas próprias Ordenações.

A segunda reforma, que visava garantir a aplicação desse conteúdo altamente reformador da aplicação do Direito disposto na "Lei da Boa Razão", é publicada em 1772, também por inspiração do Gabinete administrado pelo Marquês de Pombal, disposição sobre os novos estatutos universitários. Essa modificação no ensino jurídico demonstrou o adequado complemento às reformas na legislação, com a obrigatória introdução, no ensino jurídico, de ideais jusnaturalistas e do usus modernus pandectarum, que tornam possível a incursão de uma mentalidade nova às novas gerações de juristas, devidamente adaptada à compreensão do novo espírito que inspira a legislação portuguesa no que se refere aos métodos de interpretação e integração das lacunas. Ambas as medidas reformadoras, inclusive, produziram efeitos imediatos e mediatos na formulação de assentos doutrinais nos tribunais superiores de Portugal - que tinham valor normativo na atividade dos magistrados -, que se caracterizavam pela grande preocupação em formular princípios gerais na interpretação e aplicação das leis vigentes, fazendo com que a incidência do usus modernus pandectarum e, portanto, a aplicação da "Lei da Boa Razão", tivesse uma ampla penetração de cunho renovador na cultura jurídica portuguesa, bem como na brasileira.

Assim, a "Lei da Boa Razão" afastou o costume contra legem e reduziu o direito subsidiário ao direito romano do usus modernus pandectarum e, em matéria de caráter político, económico, mercantil e marítimo, às leis das nações cristãs, polidas e civilizadas. Enquanto abandonava, em certa medida, a utilização do costume, afirmou a lei como a única fonte do direito. Conservou-se, por oportuno, o critério de preenchimento de lacunas, ainda que as Ordenações possuíssem normativas apontadas como confusas ou contraditórias, inclusive com a utilização de institutos ou terminologias ultrapassadas para o período ${ }^{10}$. Após

\footnotetext{
${ }^{10}$ Curiosamente, foram as Ordenações Filipinas aquelas que mais se perpetuaram no Brasil, ao ponto de só serem, de fato, revogadas, com a edição do Código Civil de 1916. Foi essa medida que fez com que Tullio
} 
o período de estabelecimento da União Ibérica, o governo brasileiro experimenta um período de expansão territorial e econômica, na qual se consubstancia a criação de vilas ao longo do litoral; na defesa do território brasileiro contra a invasão estrangeira de francesas, espanhóis e holandeses; da expansão de bandeirantes com "entradas" e "bandeiras"; do ciclo do ouro e dos metais preciosos; do desenvolvimento de outras indústrias, como a madeireira, do açúcar, entre outras; e o desenvolvimento do comércio, que, desde 1661, era interno, apenas derivado para a Metrópole, e era proibido o comércio com navios estrangeiros (FERREIRA, 1962, p. 170).

$\mathrm{Na}$ seara tributária, verifica-se a existência de tributos ordinários e de tributos extraordinários. Os tributos ordinários eram aqueles cobrados para despesas comuns, vinculadas a fatos geradores do cotidiano. Os tributos extraordinários, por sua vez, eram cobrados em caráter transitório, e destinados a cobrir despesas excepcionais, como obras ou serviços urgentes na colônia, e mesmo para complementar a arrecadação ordinária, quando as evasões de rendas se tornavam por demais exageradas (HUGO, 1945, p. 158). Por sua vez, a divisão não escapava dos tributos extraordinários, que eram regidos, conforme mencionado anteriormente, para solver situações excepcionais, como aquelas em que Portugal ou o Brasil necessitavam cobrir indenizações de guerras; fazer despesas com a manutenção de tropas e fortalezas; atender despesas com casamentos de membros da Família Real; com construções de cidades e organização de esquadras ou comboios, entre outros. Os tributos continuam cobrados pelos "rendeiros", verdadeiros cobradores de rendas, que possuíam poderes singulares, como o de prender os remissos ou em atraso com suas obrigações fiscais, bem como, em razão da natureza in natura do tributo, colhiam produtos como açúcar, tabaco, cravo, pano de algodão, farinha, carne salgada, couro, pau-brasil, entre outros. Como a moeda corrente em solo brasileiro, naquele período, era o "real" ou o "cruzado portugueses, esta não poderia ser utilizada como pagamento tributário.

\section{CONCLUSÃO}

Ascarelli, um dos responsáveis - de forma precursora - pela inserção da doutrina jurídico-tributária no País, afirmar que o Brasil apresenta, como uma de suas características mais marcantes, o fato de ter apresentado uma legislação de cunho medieval até meados do século XX, quando, nos países europeus, por exemplo, as codificações já eram tendência desde o início do século XIX. Conf. ASCARELLI, Tullio. Studi di diritto comparato e in tema di interpretazione. Milão: Giuffrè, 1952., p. 81-83. Acerca do papel exercido por Tullio Ascarelli na construção da doutrina jurídico-tributária no Brasil, principalmente com sua atuação em sala de aula, ver. NOGUEIRA, Ruy Barbosa. Tullio Ascarelli e o Direito Tributário do Brasil. Direito Tributário atual, São Paulo, v. 10, p.2703-2743, 1990. 
Conclui-se, diante de todo o exposto, que o sistema tributário brasileiro carece de consideração sobre a pré-estruturação essencial das regras jurídicas, por meio da autoorganização da sociedade. Essa medida é indispensável para a viabilidade de qualquer criação de regras e, sem isso, a jurisdição não poderia funcionar. Por exemplo, tornou-se difícil, em muitos campos do Direito Tributário, distinguir a criação de Direito em si da criação de regras, normas jurídicas de normas sociais, regimes jurídicos de regimes complementares, de um suposto planejamento tributário, diante de interpretações controversas sobre hipóteses de incidência, fatos geradores, bases econômicas previstas na Constituição da República Federativa do Brasil, de 1988, que são transmutados, a todo momento, por decisões judiciais controversas. E quando, não muito, encontram-se empecilhos de interpretação administrativa equivocados. Um sistema tributário brasileiro, ou mesmo uma organização fiscal efetiva, praticamente inexistiam em período colonial. Os principais órgãos de administração dos negócios da Real Fazenda - Juntas da Fazenda, que continham o Ouvidor-Geral, o Intendente da Marinha, o Procurador da Coroa e um escrivão, sob a presidência do Capitão-Mor; as Alfândegas, administradas por um Juiz e um Ouvidor, com auxílio de escrivães, tesoureiros, oficiais e guardas; e as Mesas de Inspeção, que examinavam, classificavam e designavam a quantidade e a qualidade dos gêneros que se pretendia exportar - não eram suficientes para a determinação de uma metodologia própria da organização político-administrativa do Brasil, e, ainda assim, legitimavam-se por intermédio da Carta Régia portuguesa. Mas um sistema tributário efetivamente brasileiro permanecia ausente. E a vinda da família real portuguesa para terras brasileiras não modificou, sobremaneira, este panorama.

Isso não deveria ser entendido como uma manifestação da crise de uma análise teoricamente equivocada do direito que poderia ser resolvida usando instrumentos da teoria de sistemas que são mais sofisticados. Em vez disso, isso tem de ser interpretado como sinal de um inevitável "pluralismo de regras" dentro de contextos globais de ação. Neste ponto fica claro que a criação de direito só é possível sobre uma base de convenções sociais que, por sua vez, pressupõem um repertório comum de regras já verificadas na prática. Por outro lado, toda jurisdição oriunda de decisões de tribunais tem de, em qualquer tempo, ser construída tendo em vista uma reação "adequada" a essa provisão de regras e conhecimento verificada na prática.

\section{REFERÊNCIAS BIBLIOGRÁFICAS}


ALMEIDA, Fernando Mendes de. O Direito português no Brasil. In: HOLANDA, Sérgio Buarque de (org.). A época colonial: administração, economia, sociedade. Rio de Janeiro: Bertrand Brasil, 2003, t. 1, v. 2 (col. História geral da civilização brasileira).

AMED, Fernando José; NEGREIROS, Plínio José Labriola de Campos. História dos tributos no Brasil. São Paulo: Edições SINAFRESP, 2000.

ANGELOZZI, Gilberto Aparecido. História do Direito no Brasil. Rio de Janeiro: Freitas Bastos Editora, 2009.

AVELAR, Hélio Alcântara. História administrativa e econômica do Brasil. Rio de Janeiro: MEC/Fename, 1976.

AVELAR, Hélio de Alcântara. História administrativa do Brasil: administração pombalina. Brasília: Editora Universidade de Brasília - FUNCEP, 1983.

BALTHAZAR, Ubaldo Cesar. História do tributo no Brasil. Florianópolis: Fundação Boiteux, 2005.

CARBONNIER, Jean. Essais sur les lois. Paris: Répertoire du Notariat Defrénois, 1979.

CAVALCANTI, Themistocles Brandão. Aspectos da cultura jurídica brasileira. Revista de Ciência Política, Rio de Janeiro, v. 2, n. 23, p.11-20, maio/ago. 1980.

CUNHA, Fernando Whitaker da. O Direito português em 1500. Revista da EMERJ, Rio de Janeiro, v. 3, n. 10, 2000.

FAORO, Raymundo. Os donos do poder - formação do patronato político brasileiro. 3. ed. São Paulo: Editora Globo, 2001.

FERREIRA, Benedito. A história da tributação no Brasil: causas e efeitos. Brasília: Senado Federal, 1986.

FERREIRA, Waldemar Martins. História do Direito brasileiro. São Paulo: Max Limonad, 1956, t. IV.

GOMES, Orlando. Raízes históricas e sociológicas do código civil brasileiro. Salvador: Universidade da Bahia, 1958.

HUGON, Paul. O imposto. São Paulo: Renascença, 1945.

MENDONÇA, Maria Lírida Calou de Araújo e. Entre o público e o privado: as Organizações Sociais no Direito Administrativo brasileiro e participação democrática na Administração Pública. 2004. 199 f. Tese (Doutorado) - Curso de Pós-graduação em Direito Público, Universidade Federal de Pernambuco, Recife, 2004.

MENDONÇA, Maria Lírida Calou de Araújo e. A evolução da Administração Pública brasileira e sua interrelação com o Direito Privado. In: COSTA, Ana Edite Olinda Norões. Direito Administrativo: análises e reflexões. Fortaleza: Universidade de Fortaleza, 2008.

MORAES, Bernardo Ribeiro de. Compêndio de Direito Tributário. 5. ed. Rio de Janeiro: Forense, 1996, v. I.

MOTA, Carlos Guilherme. Presença francesa em Recife, em 1817. Caravelle. Cahiers du monde hispanique et luso-brésilien, Paris, v. 15, p.47-56, 1970.

NOGUEIRA, Ruy Barbosa. Tullio Ascarelli e o Direito Tributário do Brasil. Direito Tributário atual, São Paulo, v. 10, p.2703-2743, 1990. 
PAIM, Antônio. História das Idéias Filosóficas no Brasil. 3. ed. São Paulo: Convívio, 1984.

PAPACHRISTOS, Athanase $\mathrm{C}$. La réception des droits privés étrangers comme phénomène de sociologie juridique. Paris: Librarie Générale de Droit et de Jurisprudence, 1975.

RIBEIRO, Joaquim. História administrativa do Brasil: a união ibérica; a administração do Brasil holandês. Brasília: Editora Universidade de Brasília -FUNCEP, 1983.

SALDANHA, Nelson Nogueira. As constantes axiológicas da cultura e da experiência jurídica brasileiras. Ciência \& Trópico, Recife, v. 1, n. 15, p.55-64, jan./jun. 1987.

SOUSA, José Pedro Galvão de. Introdução a história do Direito político brasileiro. São Paulo: Reconquista, 1954

SOUSA, Rubens Gomes de. O sistema tributário federal. Revista de Direito Administrativo, Rio de Janeiro, v. 72, p.1-22, jan./mar. 1963

TAPAJÓS, Vicente Costa Santos. História administrativa do Brasil: a política administrativa de D. João III. Brasília: Editora Universidade de Brasília/FUNCEP, 1983, t. II.

TARDE, Gabriel. Les lois de l'imitation: étude sociologique. 4. Ed. Paris: Félix Alcan, 1904.

TAVARES, Ana Lucia de Lyra. O Direito comparado na história do sistema jurídico brasileiro. Revista de Ciência Política, Rio de Janeiro, v. 33, n. 1, p.55-90, nov. 1989/jan. 1990.

TOLLENARE, Louis-François. Notas dominicais tomadas durante uma viagem em Portugal e no Brasil em 1816, 1817 e 1818. Salvador: Livraria Progresso Editora, 1956.

VALLADÃO, Haroldo. L'étude et l'enseignement du droit compará au Brésil - XIXème et XXème siècles. In: Livre du Centenaire de la Société de Législation Comparée. Paris: Librairie générale de droit et de jurisprudence, 1971, t. II.

WIEACKER, Franz. A History of Private Law in Europe: with particular reference to Germany. Oxford: Clarendon Press, 1996. 